\title{
Kaposi's Sarcoma and HIV-Tat: Challenges to Antiangiogenesis Research

\author{
Adriana Albini ${ }^{* \ddagger 1}$, Roberto Benelli ${ }^{1}$, Laura Paleari ${ }^{1}$, Ulrich Pfeffer ${ }^{1}$, \\ Nicoletta Ferrari ${ }^{1}$ and Douglas Noonan ${ }^{2}$
}

\author{
Address: ${ }^{1}$ Lab Molecular Oncology - IST-Ist. Naz.Ricerca sul Cancro- - 16132 Genova and ${ }^{2}$ University of Insubria, Varese (I) \\ Email: Adriana Albini* - adriana.albini@istge.it \\ * Corresponding author ¥Presenting author
}

from 2005 International Meeting of The Institute of Human Virology

Baltimore, USA, 29 August - 2 September 2005

Published: 8 December 2005

Retrovirology 2005, 2(SuppI I):S4I doi:I0.1 186/I742-4690-2-SI-S4I

Kaposi's sarcoma (KS) is characterized by an abnormal growth of blood vessels. KS was found mainly in older men of Mediterranean or African origin (classic KS) or in patients after organ transplantation (iatrogenic KS). However, in the early 1980s, an aggressive epidemic form, linked to AIDS, was noticed and was one of the first clues to the existence of HIV-1 pandemy. The link between KS occurrence and HIV has raised multiple hypotheses. The drastic reduction of KS after the introduction of HAART, suggests HIV as a powerful co-factor for KS progression. We and others have contributed to the elucidation of KS cell nature and the possible involvement of extracellular HIV Tat. Tat is proangiogenic and is a true promoter of KS lesions acting as a VEGFR2 ligand both on KS and endothelial cells, in addition Tat is able to bind and activate chemokine receptors on monocytes and granulocytes causing a pro-inflammatory status. Evaluation of the effects of extracellular Tat on KS cells by microarray analysis after $24 \mathrm{~h}$ of incubation shows an interesting clustering of gene products involved in signal transduction, especially GTP-ase, Kinase and cAMP activity, confirming that Tat acts extracellularly by ways that are probably unrelated to its nuclear activity. KS occurrence is reduced by HAART but still present and in Africa is one of the most frequent oncologic disease. To find suitable drugs with low toxic impact on KS patients, we have tested several drugs and gene therapy approaches in in vivo models. 